\title{
Focusing on individual requirements - A shift in ventilation strategy. From the open to the closed lung.
}

\author{
Kanishka Indraratna ${ }^{*}$ \\ Consultant Anaesthetist ${ }^{1 *}$, Sri Jayewardenapura General Hospital, Kotte, Sri Lanka.
}

Intermittent positive pressure ventilation has been practiced since the early $1950 \mathrm{~s}$. It has proved to be lifesaving in many instances. However, in ARDS, the improved outcomes which were anticipated have not been achieved. In the 1990s mortality was in the range of $40 \%$ to $70 \%$. Subsequently it has been around 30\%-40\%. ${ }^{1}$ Many associated causes may be responsible for this. Another factor may be the occurrence of ventilator induced lung injury in these patients. ARDS may be a manifestation of our treatment because of ventilator induced lung injury rather than the cause of the underlying disease. ${ }^{2}$

Large pressures are required to expand collapsed alveoli which are surrounded by normal alveoli. These forces can cause structural damage and also cause the production of various mediators. These cause ARDS. ${ }^{3}$ Ventilator induced lung injury has the pathological features of, the presence of inflammatory cells, increased permeability and oedema. ${ }^{4}$ Large tidal volumes, over distension, generation of shear forces, regional variations in ventilation, repetitive collapse and re-expansion of alveoli, displacement and inactivation of surfactant, secretion of intracellular mediators are some of the mechanisms identified with the causation of ventilator induced lung injury.

It has been shown, that when ventilation was provided in the presence of collapsed alveoli, there was more damage, than when the lung was fully open. $^{2}$

*Correspondence: Kanishka Indraratna

E mail: kanishka.indraratna@yahoo.com

https://orcid.org/0000-0002-5458-9936

DOI: http://doi.org/10.4038/slja.v27i2.8474

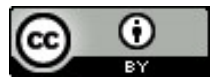

To prevent lung injury the whole lung should be opened up and kept open. ${ }^{2}$ This would facilitate more homogenous ventilation of alveoli. The lung is opened up by a recruitment maneuver with a pressure of about $45-60 \mathrm{~cm} \mathrm{H}_{2} \mathrm{O}$ and kept open with a high PEEP. ${ }^{5}$ This is the open lung strategy.

To prevent ventilator induced lung injury several strategies have been employed, commonly termed as lung protective ventilation. These include low tidal volume ventilation, high PEEP to achieve oxygenation goals, ${ }^{6}$ and recruitment maneuvers. ${ }^{7}$

PEEP may increase oxygenation by increasing functional residual capacity, recruiting alveoli, redistributing extravascular lung water, and improving ventilation perfusion matching. ${ }^{7}$ By expansion of the collapsed alveoli and keeping them open, the tidal volume would be more uniformly distributed and thereby the airway pressures would be reduced.

Lung recruitment is a component of lung protective ventilation strategy. This is performed to open up the collapsed alveoli. Recruitment is by transiently increasing the transpulmonary pressure. ${ }^{8}$

Therefore, recruitment maneuvers and PEEP have been important tools in expanding collapsed alveoli, preventing collapse and keeping the recruited alveoli open. ${ }^{2}$

However, recent clinical evidence does not unequivocally support the open lung concept. ${ }^{9,10} \mathrm{~A}$ recent trial concluded that recruitment combined with high PEEP increased mortality in ARDS. ${ }^{11}$ The over distension caused by these maneuvers may cause more harm than atelectrauma and shear forces. ${ }^{12}$ Insufficient PEEP may not be able to prevent alveolar collapse and cyclical reopening. Excessive PEEP may cause over distension and cause more damage. ${ }^{13}$ 
With the use of high PEEP the mortality was higher in patients with moderate ARDS. The power delivered to a lung with moderate ARDS is much higher than to a lung with severe ARDS. ${ }^{12}$ The driving pressure reduced by only $2 \mathrm{cmH}_{2} \mathrm{O} .{ }^{11}$ This implies that the recruitment was not adequate. PEEP causes a sustained maintenance of recruitment of collapsed alveoli. However, with the PEEP required to keep these recruited lungs open, less diseased or normal alveoli will be over distended

Recent studies have shown that alveolar over distension, causes the release of more inflammatory mediators than the repeated cyclical pattern of ventilation. ${ }^{14}$

Therefore, it is apparent that recruitment and high PEEP and the open lung concept will not be successful in all patients with ARDS, particularly those with mild to moderate ARDS. High PEEP has the disadvantages of overdistension of healthy alveoli, oedema formation, poor lymphatic drainage, and effects on right ventricular function. ${ }^{15}$ Recruitment maneuvers, increase the aerated alveoli by expanding them and reduce the selective overdistension of healthy alveoli. But at the same time during the maneuver the normal alveoli can be overdistended and lead to lung injury. ${ }^{8}$ Recruitment should be attempted only in the presence of lifethreatening hypoxia. ${ }^{8}$

It is now suggested that "closing the lungs and resting them" may protect against ventilator induced lung injury. ${ }^{15}$

With this concept, the ventilation strategy is,

1. Not attempting to recruit all the collapsed alveoli

2. Avoid opening and closing of collapsed alveoli

3. Ventilation of aerated lung and resting the collapsed and consolidated alveoli. ${ }^{15}$

Therefore, the new protective strategy suggests

1. A PEEP level sufficient to keep saturation over $88 \%$

2. A low tidal volume only to ventilate the aerated alveoli

3. A respiratory rate to keep the $\mathrm{pH}$ within normal range. ${ }^{15}$
Prone positioning is a method of recruiting the dependent non-aerated lung without the use of pressure. This method improved mortality rates. ${ }^{16}$ Prone positioning should be used as a part of this strategy.

The aim of the new strategy therefore would be to cater to individual requirements, and target safe oxygen levels of $88-92 \%$ rather than universally ideal levels. PEEP levels should be aimed for that, rather than titrating against ideal oxygen levels. Recruitment is not required for moderate ARDS but only in the presence of life threatening hypoxia in severe ARDS. Early proning may help recruit lungs and improve oxygenation in a physiological approach.

The aim of closing and resting the lungs is to achieve safe oxygen levels without causing damage by non-physiological maneuvers.

In ventilating patients, it is important to identify the individual requirements, and focus on achieving safe levels of oxygenation, plateau pressure, power of ventilation and driving pressures rather than concentrating on numbers which are supposed to be ideal.

\section{References}

1. Harman E M. What are the mortality rates for acute respiratory distress syndrome? Medscape 17th October 2018

2. Lachmann B. Open up the lung and keep the lung open. Intensive care medicine 1992; 18:319-321 https://doi.org/10.1007/BF01694358 PMid:1469157

3. Mead J, Takashima T, Leith D. Stress distribution in lungs: a model of pulmonary elasticity. $J$ appl physiol1970;28:596-608

https://doi.org/10.1152/jappl.1970.28.5.596

PMid:5442255

4. Slutsky AS, Ranieri M. Ventilator induced lung injury. N Eng J Med 2013; 369:2126-2136 https://doi.org/10.1056/NEJMra1208707 PMid:24283226

5. Zee.P Gommers D. Recruitment maneuvers and higher PEEP, the so called open lung concept, in patients with ARDS. Critical care 2019. 23:73 https://doi.org/10.1186/s13054-019-2365-1 PMid:30850004 PMCid:PMC6408810

6. Acute respiratory distress syndrome network. N Eng J Med 2000;342:1301-1308 
Indraratna. Sri Lankan Journal of Anaesthesiology: 27(2):102-104(2019)

https://doi.org/10.1056/NEJM200005043421801

PMid:10793162

7. Slutsky AS, Hudson LD. PEEP or no peep lung recruitment may be the solution. N EngJMed 2006 27;354(17):1775-

https://doi.org/10.1056/NEJMe068045

PMid:16641401

8. Fan E, Wilcox E, Brower RG. Recruitment maneuvers for acute lung injury. Am j respiratory crit care med 2008;178: 1156-1163

https://doi.org/10.1164/rccm.200802-3350C

PMid:18776154

9. Briel M, Meade M, Mercat A et al. Higher vs lower positive end expiratory pressure in patients with acute lung injury and acute respiratory distress syndrome systematic review and meta-analysis. JAMA 2010;303:865-873

https://doi.org/10.1001/jama.2010.218

PMid:20197533

10. Amato MB, Meade MO, Slutsky AS, et al. Driving pressure and survival in the acute respiratory distress syndrome. N EngJMed 2015;372:747-755, https://doi.org/10.1056/NEJMsa1410639

PMid:25693014

11. Cavalcanti AB, Suzumura EA, Laranjeira LN. Effect of lung recruitment and titrated positive end expiratory pressure (PEEP) vs low PEEP on mortality in patients with acute respiratory distress syndrome. A randomized clinical trial. JAMA 2017;318: $1335-1345$

https://doi.org/10.1001/jama.2017.14171

PMid:28973363 PMCid:PMC5710484

12. Cipulli F, Vasques F, Duscio E et al. Atelectrauma or volutrauma: the dilemma. J Thora Dis 2018;10:1258-1264

https://doi.org/10.21037/jtd.2018.02.71

PMid:29707275 PMCid:PMC5906244

13. ARDSnetwork1. Ventilation with lower tidal volumes as compared with traditional tidal volumes for acute lung injury and the acute respiratory distress syndrome: The acute respiratory distress syndrome network. N Eng J Med 2000;342:13011308

https://doi.org/10.1056/NEJM200005043421801

PMid:10793162

14. Wakabayashi K, Wilson MR, Tatham $\mathrm{KC}$ et al. Volutrauma but not atelectrauma induces systemic cytokine production by lung marginated monocytes. Crit care med 42:e49-e57 https://doi.org/10.1097/CCM.0b013e31829a822a PMid:23963135

15. Pelosi P, Rocco PRM, Abreu MGD. Close down the lungs and keep them resting to minimize ventilator induced lung injury. Annual update in intensive care and emergency medicine 2018 https://doi.org/10.1186/s13054-018-1991-3 PMid:29558993 PMCid:PMC5861643

16. Guerin C, Reigner J, Richard JC et al. Prone positioning in severe acute respiratory distress syndrome. N Eng J Med 2013;368:2159-2168 https://doi.org/10.1056/NEJMoa1214103

PMid:23688302 